\title{
Analysis of androgen receptor and anti-Müllerian hormone pathways in human granulosa cells under luteinizing hormone treatment
}

\author{
Kuo-Chung Lan ${ }^{1,2,3}$, Shiuh Young Chang ${ }^{4}$, Fu-Jen Huang ${ }^{1}$, Hsin-Jung Lin ${ }^{3}$, Ching-Yuang Lin ${ }^{5}$, Ko-En Huang ${ }^{1,3}$
} and Hong-Yo Kang ${ }^{2,3^{*}}$

\begin{abstract}
Background: The objective of this study was to determine the gene expression profiles of the androgen/androgen receptor (AR) and anti-Müllerian hormone (AMH)/ Sry-related high-mobility group box 9 (SOX9) pathways in granulosa-luteal cells from patients undergoing standard in vitro fertilization (IVF) with or without recombinant luteinizing hormone ( $\mathrm{rLH}$ ) therapy.

Methods: Levels of reproductive hormones in the pre-ovulatory follicular fluid and the expression levels of LHR (luteinizing hormone receptor), AR, SOX9, AMH, AR-associated protein 54(ARA54)and ARA70 were determined in granulosa-luteal cells by real-time reverse-transcription PCR. The effects of androgen and rLH treatments on AR and AMH expression levels were also tested in vitro using $\mathrm{HO} 23$ cells.

Results: We collected 35 an 70 granulosa cell samples from patients cycled with and without rLH supplementation, respectively. The clinical outcomes were similar in patients who received rLH therapy and those who did not, though the pre-ovulatory follicular fluid levels of androstenedione, testosterone, and estradiol were significantly higher and progesterone was lower in the rLH supplementation group. Moreover, granulosa-luteal cell mRNA levels of LHR, AR, AMH, and SOX9 were significantly higher in the rLH supplementation group relative to the group that did not receive rLH supplementation. In addition, we observed significant correlations between LHR and AR mRNA expression and among $\mathrm{AR}, \mathrm{AMH}$, and SOX9 mRNA expression in granulosa-luteal cells from patients undergoing standard IVF treatment.
\end{abstract}

Conclusions: Increased expression of LHR, AR, AMH, and SOX9 is characteristic of granulosa-luteal cells from IVF/ intracytoplasmic sperm injection (ICSI) patients receiving rLH supplementation.

Keywords: Controlled ovarian stimulation, Recombinant luteinizing hormone, Androgen receptor, SOX9, Anti-Müllerian hormone

\section{Background}

Controlled ovarian hyperstimulation $(\mathrm{COH})$ is one of the pivotal steps in assisted reproductive technology (ART). The role of endogenous luteinizing hormone (LH) levels and the effect of LH on follicular maturation and pregnancy outcome during ovarian stimulation have

\footnotetext{
* Correspondence: hkang3@mail.cgu.edu.tw

${ }^{2}$ Graduate Institute of Clinical Medical Sciences, Chang Gung University, Kaohsiung, Taiwan

${ }^{3}$ Center for Menopause and Reproductive Medicine Research, Kaohsiung Chang Gung Memorial Hospital and Chang Gung University College of Medicine, Kaohsiung, Taiwan

Full list of author information is available at the end of the article
}

attracted a great deal of attention since the early years of in vitro fertilization (IVF) [1,2]. With the availability of recombinant human LH (rLH), clinicians now have the opportunity to administer two gonadotropins independently. Thus, exogenous rLH administration can be calibrated independently of recombinant follicle-stimulating hormone $(\mathrm{rFSH})$.

The use of rLH for $\mathrm{COH}$ with respect to indications, timing, and dosage has not been fully elucidated $[3,4]$. A growing body of evidence seems to indicate a beneficial effect of co-treatment with rFSH and $\mathrm{rLH}$, in particular for patients suffering pregnancy loss, poor responders

\section{Biomed Central}


[5-8] and patients of advanced age who undergo ART [6,9-13]. However, because of the relatively small sample sizes, many of these trials were underpowered for evaluating clinical pregnancy as a primary outcome and were thus inconclusive as to the benefit of $\mathrm{rLH}$ therapy. To better establish the role of LH in IVF, additional basic research and randomized, focused clinical trials are needed $[9,14,15]$.

Ovarian androgens are produced by thecal cells and exert their action in a paracrine fashion on granulosa cells. Androgen action is mediated by the androgen receptor (AR), which, like other members of the steroid receptor superfamily, interacts directly with target genes to regulate transcription [16]. Several coactivator proteins have been shown to bind steroid receptors and enhance their interaction with basal transcription factors, thereby amplifying the transcriptional activation potential of the receptor. Among these coactivators are the AR-associated protein 54 (ARA54) and ARA70 [17]. We previously proposed the possibility of a transition in androgen action from an enhancer of follicular differentiation (through the AR) to a substrate for estrogen synthesis (through aromatase) at the time of oocyte retrieval [17].

Sry-related high-mobility group box (SOX) proteins make up a large family of transcription factors that share a homologous high-mobility group (HMG) DNA-binding domain and are key regulators of many developmental and tissue-specific processes. In the developing gonad, SOX9 plays a critical role in male sex determination by stimulating the expression of anti-Müllerian hormone (AMH) [18]. Recent clinical evidence showed that serum $\mathrm{AMH}$ levels might be a sensitive predictive parameter of ovarian status [19]. Evidence indicates a negative role for $\mathrm{AMH}$ of pre-granulosa/granulosa cell origin in this key event and subsequent progression to the antral stage [20]. Whether intrafollicular $\mathrm{AMH}$ is involved in the autocrine/paracrine regulation of granulosa and theca cell function in pre-ovulatory antral follicles remains unclear. Notably, the poor responders who benefit from cotreatment with rFSH and rLH [3,5-8] usually also exhibit extremely low serum AMH levels [19]. The "two-cell -two-gonadotropin" theory posits that ovarian theca cells stimulated by LH produce androgens, which are then converted by granulosa cells into estrogens under FSH stimulation [21]. However, the action of LH on follicular development is unlikely to be limited to providing an androgen substrate for aromatization. In fact, LH also direct stimulates and modulates folliculogenesis [22]. However, the efficacy of rLH in the follicular fluid microenvironment and on luteinized granulosa cells has been less thoroughly assessed, and studies focusing on the interaction between $\mathrm{LH}$, androgen/AR and AMH/SOX9 in granulosa cells are limited [23-27]. Our aim in this study was to examine whether $\mathrm{rLH}$ therapy affects the gene expression profiles of the androgen/AR or AMH/ SOX9 endocrine and paracrine hormonal signaling pathways in human luteinized granulosa cells.

We measured the expression levels of the luteinizing hormone receptor (LHR), AR, AR coactivators, SOX9, and $\mathrm{AMH}$ in granulosa cells collected from IVF/ICSI patients on the gonadotropin-releasing hormone agonist (GnRHa) protocol for ovarian stimulation, with or without rLH co-treatment with rFSH. In addition, we treated the human granulosa cell line HO-23 with $\mathrm{rLH}$ or androgen in vitro to investigate whether the gene expression profiles of the AR and AMH pathways were regulated by both $\mathrm{LH}$ and androgen.

\section{Methods}

\section{$\mathrm{COH}$ Protocol}

539 Patients undergoing their first ART treatment with a long $\mathrm{COH}$ protocol were enrolled in the study. This study was approved by the Ethics Committee of Chang Gung Memorial Hospital. Approval from the institutional review board was obtained for the analysis of this series (CGMH94-360). The study included patients who underwent IVF/intracytoplasmic sperm injection in our institution between March 1, 2004 and September 30, 2006. Within this study period, 35 patients received $\mathrm{rLH}$ supplementation cycles (12 patients with antral follicle count $(\mathrm{AFC})<6 ; 2$ patients with previous intrauterine insemination (IUI) poor response history; 7 patients with age $>35$ years old; 10 patients with mid-follicular serum estradiol $<100 \mathrm{pg} / \mathrm{mL}$ or $\mathrm{LH}<0.5 \mathrm{mIU} / \mathrm{mL} ; 2$ patients with poor follicular growth rate in the mid-follicular phase; 1 patient with deep infiltrating endometriosis history and 1 patient due to obesity). To match appropriate candidates to compare outcome efficiency, a 2:1 individual matching case-control design [28] was used to recruit 70 patients who did not receive $\mathrm{rLH}$ supplementation cycles but matched the demographic characteristics of the 35 patients receiving rLH therapy (Figure1). At that time, it has been suggested that recombinant LH can be used in a group of unselected IVF patients [29]. All patients provided informed consent for their participation in the molecular investigation. The $\mathrm{COH}$ procedure was followed by the standard down-regulation protocol, as published previously [30]. Briefly, GnRHa (Lupron; Abbott Australasia PTY, Ltd., Kurnell, New South Wales, Australia) was administered from the mid-luteal phase, and rFSH (Gonal-F; Serono Laboratories, Aubonne, Switzerland) was administered after pituitary desensitization was achieved. Patients received one of the following fixed starting doses (age < 35: 225 IU/day; age $\geq 35$ : 300 IU/day) of rFSH (Gonal-F, 75 IU/ampoule, Serono Laboratories, Aubonne, Switzerland) after pituitary suppression with GnRHa. Gonadotropin was administered daily for 5 days, after which the dose was individualized according to 
569 standard down-regulation long protocol cycles with granulosa cells obtained from 569 patients

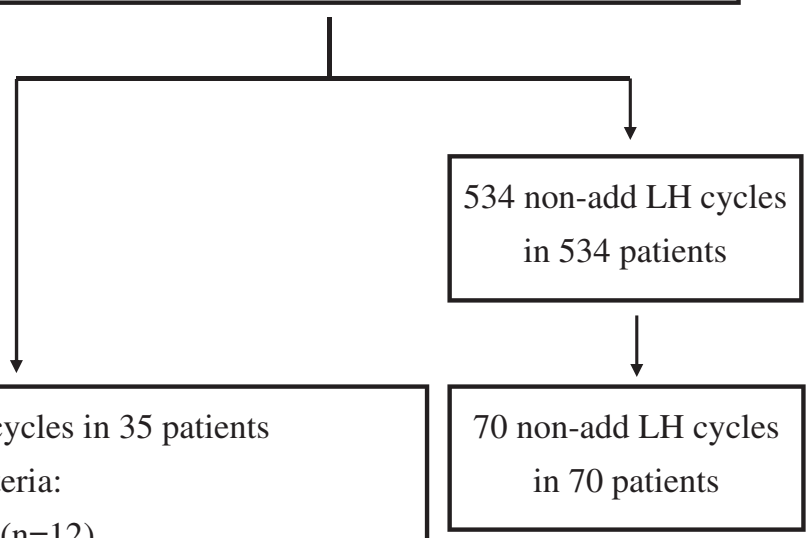

1. $\mathrm{AFC} \leq 6(\mathrm{n}=12)$

2. Previous poor IUI response $(n=2)$

3. Age $\geq 35(n=7)$

4. $\mathrm{E} 2<100 \mathrm{pg} / \mathrm{mL}$ or $\mathrm{LH}<0.5 \mathrm{mIU} / \mathrm{mL}$ in the mid-follicular phase $(n=10)$

5. Poor follicular growth rate in the midfollicular phase $(n=2)$

6. DIE History $(n=1)$

7. Obesity $(n=1)$

Figure 1 Flow diagram of 539 patients who attended the case-control study.

ovarian follicular growth, as in our previous reports [30]. Monitoring of transvaginal ultrasound and serum estradiol (E2) was performed every 2 to 3 days starting on the $5^{\text {th }}$ day of stimulation. After 6 days of $\mathrm{rFSH}$ stimulation, patients who had ever received co-treatment with $75 \mathrm{IU}$ of rLH (Luveris; Merck Serono SA, Aubonne Branch, Switzerland) were submitted to the rLH supplementation group. rFSH, with or without $\mathrm{rLH}$, was continuously administered until 2 of the dominant follicles reached $18 \mathrm{~mm}$, and then the patients received $250 \mu \mathrm{g}$ of hCG (Ovidrel; Merck Serono, Inc., West Orange, NJ, USA).

\section{Collection of primary human granulosa cells}

Thirty-four to 36 hours after hCG administration, follicular fluid (FF) and luteinized granulosa cells were collected by means of transvaginal ultrasound-guided oocyte retrieval. A double-lumen needle was used for aspiration because the puncture needle used to obtain a sample of uncontaminated luteinized granulosa cells was not withdrawn before entering the next follicle. Only the first aspirate of pre-ovulatory follicles without blood contamination from one ovary was used for this study. After follicular aspiration, the cumulus-oocyte complexes were separated for IVF, and the luteinized granulosa cells were flushed with IVF medium to disperse the cells. The cells were then immediately transported to the laboratory. The follicular fluid was stored under the same conditions as serum. The FF samples were analyzed for testosterone, estradiol, progesterone, and androstenedione. The dispersed cells were transferred to a $15-\mathrm{mL}$ centrifuge tube containing $4 \mathrm{~mL}$ of Histopaque 1077 (Sigma Chemical Co., St. Louis, MO, USA). Human luteinized granulosa cells were separated from red blood cells by centrifugation at $600 \times \mathrm{g}$ for 10 minutes. Granulosa cells formed a thin layer between the Histopaque and the medium [31] and were collected as previously reported [17].

\section{Cell lines and culture conditions}

The HO23 human immortalized luteinized granulosa cell line, provided by Dr. Abraham Amsterdam, Weizmann Institute of Science, Rehovot, Israel [32], was used for in vitro analyses. HO23 cells were established 
by triple transfection of SV40 DNA, the Ha-ras oncogene, and a temperature-sensitive (ts) mutant of the p53 tumor suppressor gene (p53val135) in primary granulosa cells obtained from IVF patients. The cells were maintained at $37^{\circ} \mathrm{C}$ and $5 \% \mathrm{CO}_{2}$ in Dulbecco's minimal essential medium (DMEM)/Ham's F12 (1:1), supplemented with 5\% fetal calf serum and antibiotics $(100 \mathrm{IU} / \mathrm{mL}$ penicillin and $100 \mathrm{mg} / \mathrm{mL}$ streptomycin). To test the effect of rLH or androgen on AR and AMH expression, cells $\left(5 \times 10^{5}\right)$ were seeded on 100-mm culture dishes and incubated for 24 hours. The media were then removed, and the cells were reincubated in medium supplemented with charcoaldextran-treated serum and then treated with different concentrations of DHT or rLH for 24 hours.

\section{RNA extraction}

Total RNA was extracted from granulosa cells $\left(5 \times 10^{5}\right)$ using TRIzol reagent (Gibco-BRL, Grand Island, NY, USA). Briefly, $1 \mathrm{~mL}$ of TRIzol was added to the granulosa cells. The mixture was pipetted and allowed to sit for 5 minutes at room temperature. Chloroform $(0.2 \mathrm{~mL})$ was added, mixed, and allowed to incubate at room temperature for 3 minutes. The mixture was then processed by centrifugation at $12,000 \times \mathrm{g}$ for 15 minutes, and the supernatant was transferred to a fresh tube. Isopropanol $(0.5 \mathrm{~mL})$ was added, mixed, and incubated for 10 minutes at room temperature. The solution was then processed by centrifugation at $12,000 \times \mathrm{g}$ for 10 minutes, and the RNA was purified.. The pellet was washed once with $70 \%$ ethanol, resuspended in $\mathrm{H}_{2} \mathrm{O}$, and stored at $-80^{\circ} \mathrm{C}$. The concentrations of the RNA samples were determined by measuring the absorbance at $260 \mathrm{~nm}$ in a spectrophotometer $\left(\mathrm{DU}^{\circledR}\right.$ 640B, Beckman Coulter, USA).

\section{CDNA synthesis}

Two micrograms of total RNA from the sample preparation were reverse-transcribed in $25 \mu \mathrm{L}$ as follows: 0.1 $\mu \mathrm{g}$ of random hexamer primers (Amersham Pharmacia Biotech, Inc., Buckinghamshire, UK) were denatured for 10 minutes at $70^{\circ} \mathrm{C}$ in a Gradient Cycler (DNA Engine, Watertown, MA, USA), and then the reverse transcription reaction was performed at $42^{\circ} \mathrm{C}$ for 1 hour by adding $5 \times$ reverse transcriptase buffer $(500 \mathrm{mM}$ of each dNTP, $3 \mathrm{mM} \mathrm{MgCl}_{2}$, $75 \mathrm{mM} \mathrm{KCl}$, and $50 \mathrm{mM}$ Tris- $\mathrm{HCl}$ [pH 8.3]), 1 mM dNTP (Promega, Madison, WI, USA), 10 IU RNase inhibitor (Promega), and $100 \mathrm{U}$ MMLV reverse transcriptase (Promega). The reverse transcriptase was inactivated by heating at $95^{\circ} \mathrm{C}$ for 5 minutes and cooling at $4^{\circ} \mathrm{C}$ for 5 minutes.

\section{Quantitative RT-PCR}

Specific PCR amplification products were detected using an ABI PRISM 7700 sequence detector system (Perkin-
Elmer Applied Biosystems, Los Angeles, CA, USA) and the SYBR green PCR master mix kit (Applied Biosystems, Foster City, USA), according to the manufacturer's protocol. The forward and reverse primer sequences for AR, AR co-factors, SOX9, AMH, LHR and B-actin and $18 \mathrm{~S}$ are listed in Table 1. Duplicate experiments were performed for each set of experimental conditions, and we retested any sample with a $>1 \%$ coefficient of variation for the $\mathrm{Ct}$ value. Quantitative values are obtained from the threshold cycle $(C t)$ number at which the increase in signal associated with an exponential growth of PCR product starts to be detected (using 7500 Fast System SDS software (Applied Biosystems)), according to the manufacturer's manual. The precise amount of total RNA added to each reaction (based on absorbance) and its quality (i.e., lack of extensive degradation) are both difficult to assess. We quantified $ß$-actin or $18 \mathrm{~S}$ gene transcripts as an endogenous RNA control, and normalized each sample with respect to its $ß$-actin or $18 \mathrm{~S}$ content. Final results, express as $N$-fold differences in target gene expression relative to the $\beta$-actin gene termed " $N$ target," are determined as follows: $N$ target $=2^{\Delta \mathrm{Ct} \text { sample }}$ where the $\Delta \mathrm{Ct}$ values of the sample were determined by subtracting the average $\mathrm{Ct}$ value of the target gene from the average $\mathrm{Ct}$ value of the $ß$-actin or $18 \mathrm{~S}$ gene in each sample.

\section{Statistical analysis}

Data analyses were performed with SPSS 10.0 software (Statistical Package for Social Sciences, Inc., Chicago, IL, USA). Continuous data were summarized as the mean \pm

Table 1 Oligonucleotide primer sequences for LHR, AR, AMH, SOX9, ARA54, ARA70 and $\beta$-actin used in real-time quantitative RT-PCR

\begin{tabular}{|c|c|}
\hline Gene & Oligo-sequence $\left(5^{\prime} \rightarrow 3^{\prime}\right)$ \\
\hline \multirow[t]{2}{*}{ LHR } & F: TCA.ATT.CTT.GTG.CCA.ATC.CA \\
\hline & R: CCA.TTT.TTG.CAG.TTG.GAG.GT \\
\hline \multirow[t]{2}{*}{$A R$} & F: TCA.CCG.CAC.CTG.ATG.TGT.G \\
\hline & R: ACA.TGG.TCC.CTG.GCA.GTC.TC \\
\hline \multirow[t]{2}{*}{$\mathrm{AMH}$} & F: AGC.TGT.GGG.CAC.CAG.TGG. \\
\hline & R: GCT.CTT.GTG.GGC.TGC.CTG. \\
\hline \multirow[t]{2}{*}{ sox 9} & F: GCA.AAG.GAG.ATG.AAA.TCT.GTT.CTG \\
\hline & R: AAG.GTT.AAC.TGC.TGG.TGT.TCT.GAG.A \\
\hline \multirow[t]{2}{*}{ ARA54 } & F: TCT.GCC.TCC.ACT.TGT.GCT.GA \\
\hline & R: GCC.ACG.GTG.TTC.TTC.CCA.TA \\
\hline \multirow[t]{2}{*}{ ARA70 } & F: TGG.AGC.TTG.CTA.TTG.GTG.GAG \\
\hline & R: CAG.GTG.ACG.GCT.TAT.GCA.ACT \\
\hline \multirow[t]{4}{*}{ B-actin $18 S$} & F: TCA.CCC.ACA.CTG.TGC.CCA.TCT.ACG.A \\
\hline & R: CAG.CGG.AAC.CGC.TCA.TTG.CCA.ATG.G \\
\hline & F:GTA.ACC.CGT.TGA.ACC.CCA.TT \\
\hline & R:CCA.TCC.AAT.CGG.TAG.TAG.CG \\
\hline
\end{tabular}


standard deviation (SD). For the purpose of this analysis, correlations in gene expression were examined. A multiple regression analysis with the stepwise forward procedure (multivariate analysis) was used to identify independent factors and to test for interactions between the covariates. The clinical outcome comparison used the Mann-Whitney rank-sum test for the comparison of means and the Fisher's exact test for proportions. All $P$ values were two-sided, and $P<0.05$ was considered statistically significant.

\section{Results}

The study population comprised two groups of patients. One group (35 patients) received rLH supplementation cycles during the IVF procedure, while the control group (70 patients) did not. The two groups were comparable in terms of age, BMI, mean duration of infertility, indication for treatment, days of FSH treatment, endometrial thickness, estradiol and progesterone levels on the day of hCG administration, and the number of oocytes and mature oocytes retrieved (Table 2).
We found that the fertilization rate, mean number of embryos transferred, and clinical pregnancy rate per transfer were similar between the two groups. The serum LH level on the day of hCG administration was the only parameter to show a statistically significant difference between the two groups $(2.6+/-1.6 \mathrm{mIU} / \mathrm{mL}$ vs. $1.9+/-1.2 \mathrm{mIU} / \mathrm{mL}, P=0.021$; Table 2 ). However, the concentrations of androstenedione, testosterone, estradiol and progesterone in the pre-ovulatory dominant follicular fluid were significantly different between groups. Follicular fluid levels of androstenedione $(76.4+/-43.2$ vs. $54.1+/$ 42.6), testosterone (10.1+/- 3.5 vs. $9.4+/-6.0)$, and estradiol $(336619.8+/-366528.9$ vs.195014.7 +/- 257784.7) were higher, and progesterone was lower $(10337.9+/-5138.1$ vs. $11974.4+/-20806.6)$ in the rLH supplementation groups (Table 3).

We next examined whether the expression levels of potential genes involved in the androgen and AMH pathways were influenced by $\mathrm{rLH}$ supplementation during $\mathrm{COH}$. The mRNA levels of the LH receptor (LHR), AR, SOX9, AMH, ARA54 and ARA70 were quantified by real-time RT-PCR in luteinized granulosa cell samples obtained

Table 2 Comparison of patients treated with Add-rLH or Non-Add-rLH IVF down-regulation regimens

\begin{tabular}{|c|c|c|c|}
\hline Transfer & Add-rLH cycles & Non-Add-rLH cycles & $P$ \\
\hline No. patients & 35 & 70 & \\
\hline Age of female partners (yrs) & $33.4+/-4.1$ & $33.2+/-4.2$ & ns \\
\hline Body mass index & $21.5+/-3.1$ & $21.6+/-3.1$ & ns \\
\hline \multicolumn{4}{|l|}{ Infertility } \\
\hline Primary (\%) & $68.6(24 / 35)$ & $55.7(39 / 70)$ & ns \\
\hline Secondary (\%) & $31.4(11 / 35)$ & $44.3(31 / 70)$ & ns \\
\hline \multicolumn{4}{|l|}{ Reason for infertility (No. of patients) } \\
\hline Tubal factor & 11 & 23 & ns \\
\hline Male factor & 17 & 32 & ns \\
\hline Unexplained & 3 & 2 & ns \\
\hline Combined factor & 4 & 13 & ns \\
\hline Duration of infertility (years) & $4.0+/-2.4$ & $4.0+/-3.0$ & ns \\
\hline Days of FSH treatment & $8.6+/-1.8$ & $9.1+/-1.7$ & ns \\
\hline FSH (IU) & $2062.5+/-975.0$ & $2385.0+/-855.0$ & ns \\
\hline$L H(I U)$ & $3525.0+/-225.0$ & & \\
\hline Endometrial thickness on day of hCG stimulation $(\mathrm{cm})$ & $1.4+/-0.3$ & $1.3+/-0.3$ & ns \\
\hline$L H(m / U / m L)$ on day of $h C G$ stimulation & $2.6+/-1.6$ & $1.9+/-1.2$ & 0.021 \\
\hline Estradiol $(\mathrm{pg} / \mathrm{mL})$ on day of hCG stimulation & $1681.9+/-1021.7$ & $1851.8+/-1166.2$ & ns \\
\hline Progesterone $(\mathrm{ng} / \mathrm{mL})$ on day of hCG stimulation & $1.2+/-0.4$ & $1.1+/-0.4$ & ns \\
\hline No. mature \& near-mature oocytes retrieved & $5.9+/-4.2$ & $6.5+/-3.3$ & ns \\
\hline No. mature oocytes retrieved & $3.7+/-2.7$ & $3.9+/-2.1$ & ns \\
\hline Normal fertilization rate & $77.8+/-33.1 \%$ & $79.4+/-23.3 \%$ & ns \\
\hline Mean No. embryos transferred & $2.1+/-0.6$ & $2.3+/-0.6$ & ns \\
\hline Clinical pregnancy rate per transfer & $34.2 \%(12 / 35)$ & $32.8 \%(23 / 70)$ & ns \\
\hline
\end{tabular}

Note: Values are mean \pm SD or proportion. 
Table 3 Comparison of follicular fluid concentrations at oocyte retrieval in patients treated with Add-LH or Non-Add rLH IVF down-regulation regimens

\begin{tabular}{lccc}
\hline Transfer & Add-rLH cycles & Non-Add rLH cycles & P \\
\hline No. patients & 35 & 70 & \\
Androstenedione $(\mathrm{ng} / \mathrm{mL})$ & $76.4+/-43.2$ & $94.1+/-42.6$ & 0.009 \\
Testosterone $(\mathrm{ng} / \mathrm{mL})$ & $10.1+/-3.5$ & $195014.7+/-257784.7$ & 0.021 \\
Estradiol $(\mathrm{pg} / \mathrm{mL})$ & $336619.8+/-366528.9$ & $11974.4+/-20806.6$ & 0.034 \\
Progesterone $(\mathrm{ng} / \mathrm{mL})$ & $10337.9+/-5138.1$ & & 0.007 \\
\hline
\end{tabular}

Note: Measurements were taken on the day of oocyte retrieval. Values are mean \pm SD.

from women who received (35 patients) or did not receive rLH supplementation (70 patients). The results are summarized in Figure 2 and Additional file 1: Figure S1. Of note, the expression of LHR, AR, SOX9, and AMH was significantly higher in granulosa cells obtained from women who received rLH supplementation. AR coregulators, i.e., ARA70 and ARA54, were expressed at similar levels between groups. Linear regression revealed that AMH, SOX9 and AR expression levels in granulosa cells were positively correlated (Figure 3, Figure 4 and Table 4). ARA54 and ARA70 expression levels were significantly correlated with SOX9 and AMH, respectively (Table 4). There was also a positive correlation between LHR and AR expression (Figure 3 and Table 4).

To investigate whether androgen or rLH treatment can regulate AR or AMH expression levels in vitro, the human granulosa cell line $\mathrm{HO} 23$ was treated with increasing doses of DHT $\left(0,1 \times 10^{-9} \mathrm{M}, 1 \times 10^{-8} \mathrm{M}, 1 \times 10^{-7} \mathrm{M}\right.$, or $\left.1 \times 10^{-6} \mathrm{M}\right)$ or $\mathrm{rLH}(0,0.5 \mathrm{IU} / \mathrm{mL}, 1 \mathrm{IU} / \mathrm{mL}, 1.5 \mathrm{IU} / \mathrm{mL}$, or $2 \mathrm{IU} / \mathrm{mL}$ ). Total RNA was collected 24 hours after treatment, and AR and AMH mRNA levels were measured by quantitative RT-PCR. We observed that increasing the dose of DHT tended to increase AR but decrease AMH expression in $\mathrm{HO} 23$ cells. In addition, increases in AR and $\mathrm{AMH}$

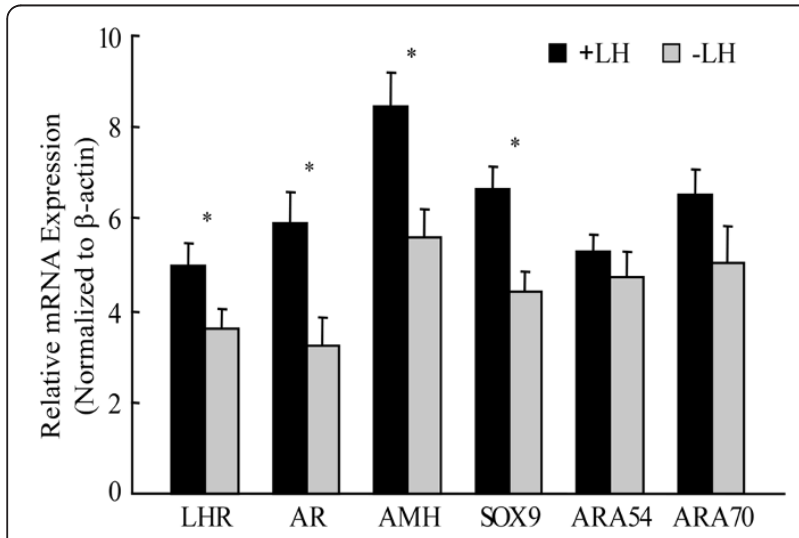

Figure 2 Quantitative analysis of LHR, AR, AMH, SOX9, ARA54 and ARA70 mRNA levels in granulosa-luteal cells collected at oocyte retrieval. Each bar represents the mean \pm SD. Concomitant detection of $\beta$-actin mRNA in the real-time RT-PCR reaction served as a reference for relative quantification. ${ }^{*} P<0.05$.
mRNA expression were observed with increasing doses of rLH (Figure 5 and Additional file 2: Figure S2).

\section{Discussion}

In the present work, we demonstrate that human granulosa-luteal cells supplemented with rLH exhibit increased expression of LHR, AR, SOX9, and AMH. This report is the first study to compare the expression profiles of genes in the androgen receptor and antiMüllerian hormone in pre-ovulatory granulosa cells from IVF/ICSI patients receiving rLH supplementation for $\mathrm{COH}$. Patients with low expression of $\mathrm{AR}, \mathrm{AMH}$, and SOX9 may require a different follow-up schedule and corresponding rLH treatment.

Little is known about the extremely complex process that generates a developmentally competent oocyte. During folliculogenesis and oogenesis, the oocyte is surrounded by granulosa cells. The two cell types communicate bidirectionally through secretion of steroid hormones and paracrine factors. This communication plays a key role in folliculogenesis and is essential for an oocyte to achieve fertilization and undergo embryogenesis [33].

It has been suggested that the expression levels of hormonally-regulated genes in granulosa cells can be used as markers for oocyte quality and hence developmental potential $[34,35]$. This development is mirrored by the FSH-induced increase in estradiol biosynthesis in granulosa cells after adequate stimulation of theca cells by LH [36]. In 2004, Westergaard et al. found that the follicular fluid concentrations of LH, estradiol and androstenedione were significantly higher and progesterone levels were significantly lower in women treated with gonadotropin plus rLH relative to women treated with recombinant rFSH alone [37]. Smitz et al. also reported that major differences in the serum and follicular fluid endocrine profiles exist after stimulation with gonadotropin and $\mathrm{LH}$, as exogenous $\mathrm{LH}$ activity may induce a different endocrine environment [38]. In agreement with these reports $[37,38]$, we found that the addition of $\mathrm{rLH}$ was associated with increased estradiol, testosterone, and androstenedione and reduced progesterone in the fluid of the dominant follicle. 

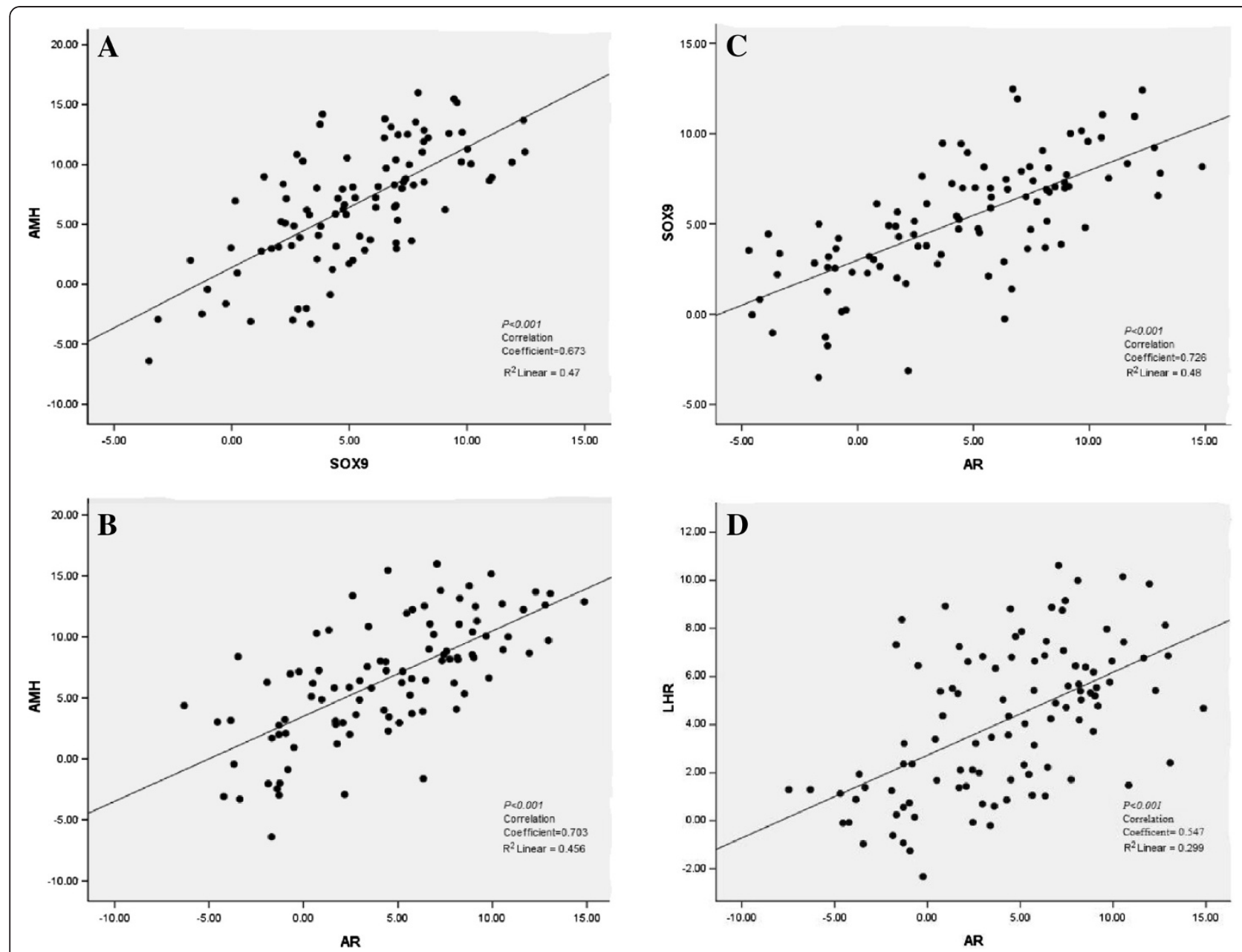

Figure 3 Linear regression revealed positive correlations in gene expression patterns. (A) AMH and SOX9 expression; (B) AMH and AR expression; (C) SOX9 and AR expression; and (D) LHR and AR expression.

$\mathrm{AMH}$ is detected in serum from women of reproductive age, and the levels vary.

Slightly with the menstrual cycle, reaching a peak value in the late follicular phase. AMH expression follows a similar pattern in humans compared with mice and rats, suggesting an important role for $\mathrm{AMH}$ in folliculogenesis [39]. Wunder et al. [40] reported that serum and follicular fluid AMH levels on the day of oocyte retrieval are correlated with reproductive outcome. From molecular point of view, AMH has been shown to be a downstream target of SOX9. Upregulation of SOX9 can promote the expression of AMH [18]. While increased intrafollicular androgen levels have been associated with significant increases in granulosa cell production of AMH [41], few studies have investigated how reproductive hormones such as LH influence the interaction between the androgen/AR and AMH/SOX9 pathways in granulosa cells.

We demonstrated that luteinized granulosa cells from IVF patients supplemented with rLH display increased LHR, AR, SOX9, and AMH expression and higher testosterone and androstenedione concentrations in the follicular fluid. Androgens are considered detrimental to the late stages of folliculogenesis [42], and hyperandrogenic polycystic ovary syndrome (PCOS) is associated with follicular development arrest and poor oocyte quality [43]. It is possible that LH may stimulate ovarian theca cells to produce androgens that act cooperatively with $\mathrm{LH}$ in a paracrine fashion on granulosa cells. Our in vitro model showed that DHT alone can downregulate AMH expression, but increased expression of $\mathrm{AR}$ and $\mathrm{AMH}$ was observed after rLH treatment. Indeed, many factors $[44,45]$ other than androgens may have affected the expression of $\mathrm{AR}, \mathrm{AMH}$ and SOX9 under rLH treatment. Increased estradiol or decreased progesterone in the follicular fluid may also influence LH-regulated granulosa cell gene expression. Further studies on interaction between LH and sex steroid hormones will be of interest.

The homogeneity of our study population is an advantage because it reduces the possibility of confounding population substructures or admixtures. However, because 


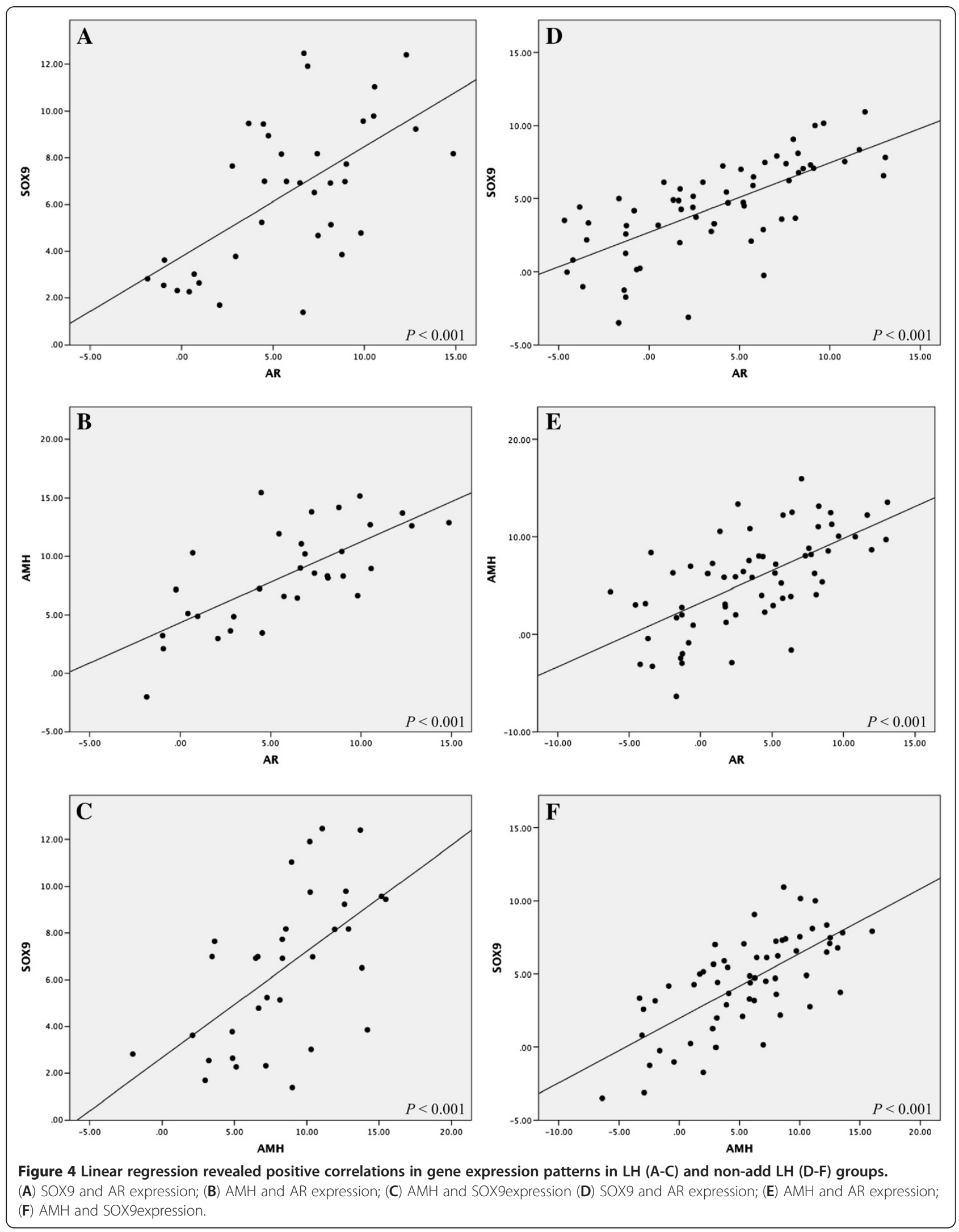


Table 4 Linear regression analysis of LHR, AR, AMH, SOX9, ARA54 and ARA70 mRNA expression in granulosa-luteal cells collected at oocyte retrieval

\begin{tabular}{|c|c|c|c|}
\hline Comparison variable & B & $95.0 \%$ Confidence interval for B & $\mathbf{P}$ \\
\hline & \multicolumn{3}{|c|}{ LHR } \\
\hline AR & 0.352 & $0.236 ; 0.468$ & $<0.001$ \\
\hline AMH & & & ns \\
\hline SoX9 & & & ns \\
\hline ARA70 & & & ns \\
\hline \multirow[t]{2}{*}{ ARA54 } & & & ns \\
\hline & \multicolumn{3}{|c|}{ AR } \\
\hline $\mathrm{AMH}$ & 0.326 & $0.160 ; 0.492$ & $<0.001$ \\
\hline SOX9 & 0.514 & $0.262 ; 0.766$ & $<0.001$ \\
\hline LHR & 0.348 & $0.129 ; 0.568$ & 0.002 \\
\hline ARA70 & & & ns \\
\hline \multirow[t]{2}{*}{ ARA54 } & & & ns \\
\hline & \multicolumn{3}{|c|}{ Sox9 } \\
\hline AR & 0.299 & $0.168 ; 0.429$ & $<0.001$ \\
\hline AMH & 0.227 & $0.105 ; 0.348$ & $<0.001$ \\
\hline LHR & & & ns \\
\hline ARA70 & & & ns \\
\hline \multirow[t]{2}{*}{ ARA54 } & 0.218 & $0.094 ; 0.341$ & 0.001 \\
\hline & \multicolumn{3}{|c|}{ AMH } \\
\hline AR & 0.370 & $0.153 ; 0.587$ & 0.001 \\
\hline SOX9 & 0.517 & $0.227 ; 0.807$ & 0.001 \\
\hline LHR & & & ns \\
\hline ARA70 & 0.181 & $0.032 ; 0.330$ & 0.018 \\
\hline \multirow[t]{2}{*}{ ARA54 } & & & ns \\
\hline & \multicolumn{3}{|c|}{ ARA70 } \\
\hline$A R$ & & & ns \\
\hline SOX9 & & & ns \\
\hline LHR & 0.388 & $0.062 ; 0.715$ & 0.020 \\
\hline AMH & 0.467 & $0.104 ; 0.619$ & $<0.001$ \\
\hline \multirow[t]{2}{*}{ ARA54 } & & & ns \\
\hline & \multicolumn{3}{|c|}{ ARA54 } \\
\hline $\mathrm{AR}$ & & & ns \\
\hline SoX9 & 0.483 & $0.280 ; 0.686$ & $<0.001$ \\
\hline LHR & & & ns \\
\hline AMH & & & ns \\
\hline ARA70 & & & ns \\
\hline
\end{tabular}

our study population was restricted to Taiwanese patients, the results may not be generalizable to other ethnicities. Although our study showed no significant differences in terms of clinical outcomes with or without rLH supplementation (Table 2), the study was underpowered to look at pregnancy rates

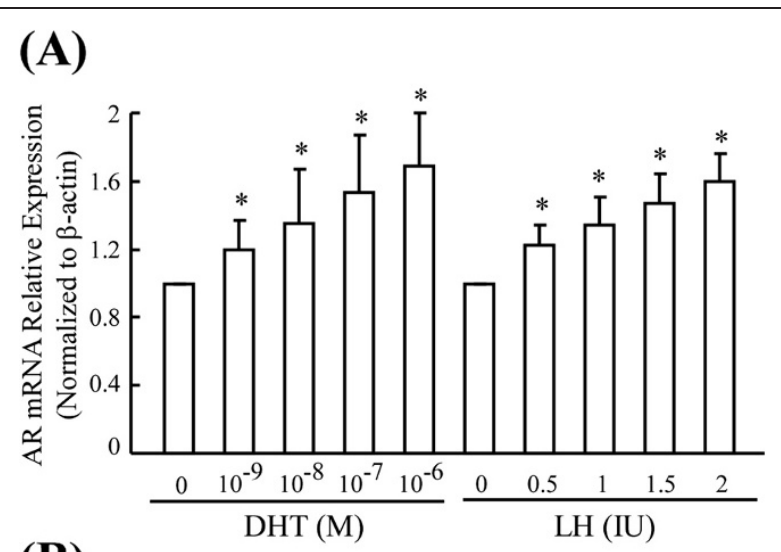

(B)

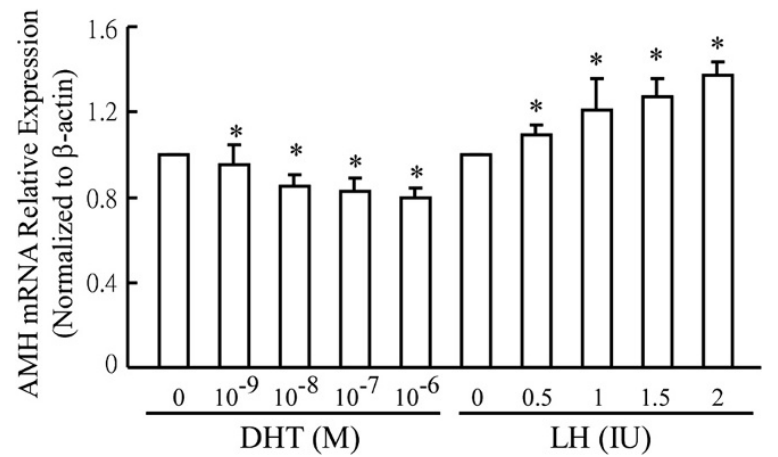

Figure 5 The effects of rLH and DHT on AR and AMH

expression. (A) AR and (B) AMH expression levels were measured in HO-23 human granulosa cells under serum-free conditions in the presence of DHT or rLH at the indicated concentrations for 24 hours. Data are expressed as the mean $+/$ - standard deviation (SD) of three different experiments. * $P<0.05$ vs. ethanol treatment; $\mathrm{DHT}$,

dihydrotestosterone; $r \mathrm{LH}$, luteinizing hormone. between the two groups. Our experiments did demonstrate that granulosa-luteal cells supplemented with rLH displayed increased expression of LHR, AR, SOX9, and AMH. As it is difficult to extrapolate the role of rLH in follicular growth and oocyte maturation based on our results, further molecular and cellular functional studies are required to investigate whether rLH therapy has unremarkable benefits or perhaps an undetermined effect on follicular growth and oocyte maturation in women.

\section{Conclusions}

In conclusion, granulosa-luteal cells from women who received $\mathrm{rLH}$ supplementation during IVF/ICSI display increased expression of LHR, AR, AMH, and SOX9. AR, SOX9 and AMH were positively correlated and may function in the hormonal milieu affecting late dominant follicles under $\mathrm{COH}$. These markers may be used as a panel of molecular markers during $\mathrm{COH}$. 


\section{Additional files}

Additional file 1: Figure S1. Quantitative analysis of $L H R, A R, A M H$, SOX9 mRNA levels in granulosa-luteal cells collected at oocyte retrieval. Each bar represents the mean \pm SD. Concomitant detection of 185 mRNA in the real-time RT-PCR reaction served as a reference for relative quantification. ${ }^{*} P<0.05$.

Additional file 2: Figure S2. The effects of $\mathrm{rLH}$ and $\mathrm{DHT}$ on $\mathrm{AR}$ and AMH expression. (A) AR and (B) AMH expression levels were measured in $\mathrm{HO}-23$ human granulosa cells under serum-free conditions in the presence of DHT or rLH at the indicated concentrations for 24 hours. Data are expressed as the mean $+/$ - standard deviation (SD) of three different experiments. Concomitant detection of 185 mRNA in the real-time RT-PCR reaction served as a reference for relative quantification * $P<0.05$ vs. ethanol treatment; $\mathrm{DHT}$, dihydrotestosterone; $r \mathrm{LH}$, luteinizing hormone.

\section{Abbreviations}

AFC: Antral follicle count; AMH: Anti-Müllerian hormone; AR: Androgen receptor; ARA54: Androgen receptor-associated protein 54; ARA70: Androgen receptor-associated protein 70; ART: Assisted reproductive technology; $\mathrm{COH}$ : Controlled ovarian hyperstimulation; Ct: Threshold cycle;

DNA: Deoxyribonucleic acid; DHT: Dihydrotestosterone; DMEM: Dulbecco's minimal essential medium; dNTP: Deoxyribonucleoside triphosphate; FF: Follicular fluid; FSH: Follicle-stimulating hormone; GC: Granulosa cell; GnRHa: Gonadotropin-releasing hormone agonist; HCG: Human chorionic gonadotropin; IUI: Intrauterine insemination; IVF: In vitro fertilization; ICSI: Intracytoplasmic sperm injection; LH: Luteinizing hormone; LHR: Luteinizing hormone receptor; PCOS: Polycystic ovary syndrome; rFSH: Recombinant follicle-stimulating hormone; rLH: Recombinant luteinizing hormone; RNA: Ribonucleic acid; RT-PCR: Reverse transcription polymerase chain reaction; SOX9: Sry-related high-mobility group box protein 9; UNG: Uracil-N-glycosylase.

\section{Competing interests}

The authors declare that they have no competing interests.

\section{Authors' contributions}

KEH and HYK supervised the research. SYC and FJH enrolled the subjects. $\mathrm{KCL}$ and $\mathrm{HYK}$ conceived and designed the experiments. $\mathrm{KCL}$ and $\mathrm{HJL}$ carried out the experiments. CYL provided HO23 cells and participated in critical discussion. The manuscript was written by $\mathrm{KCL}$ and HYK. All authors read and approved the final manuscript.

\section{Acknowledgements}

This study was supported by grants NMRPD140671, NMRPG860251and NMRPG896041 from the National Science Council of Taiwan. Our manuscript has been corrected by the English language professional service.

\section{Author details}

'Department of Obstetrics and Gynecology, Kaohsiung Chang Gung Memorial Hospital and Chang Gung University College of Medicine, Kaohsiung, Taiwan. ${ }^{2}$ Graduate Institute of Clinical Medical Sciences, Chang Gung University, Kaohsiung, Taiwan. ${ }^{3}$ Center for Menopause and Reproductive Medicine Research, Kaohsiung Chang Gung Memorial Hospital and Chang Gung University College of Medicine, Kaohsiung, Taiwan. ${ }^{4}$ Sheng An Hospital, 177 Mei-Sui East 2nd Road, Kaohsiung, Taiwan. ${ }^{5}$ College of Medicine, China Medical University, Clinical Immunology Center, China Medical University Hospital, Taichung, Taiwan.

Received: 26 July 2012 Accepted: 13 February 2013

Published: 21 February 2013

\section{References}

1. Filicori M, Cognigni GE, Samara A, Melappioni S, Perri T, Cantelli B, Parmegiani L, Pelusi G, DeAloysio D: The use of LH activity to drive folliculogenesis: exploring uncharted territories in ovulation induction. Hum Reprod Update 2002, 8:543-557.
2. Levy DP, Navarro JM, Schattman GL, Davis OK, Rosenwaks Z: The role of $\mathrm{LH}$ in ovarian stimulation: exogenous LH: let's design the future. Hum Reprod 2000, 15:2258-2265.

3. Mochtar MH, Van Der V, Ziech M, Van Wely M: Recombinant Luteinizing Hormone (rLH) for controlled ovarian hyperstimulation in assisted reproductive cycles. Cochrane Database Syst Rev 2007, 18:CD005070.

4. Kolibianakis EM, Kalogeropoulou L, Griesinger G, Papanikolaou EG, Papadimas J, Bontis J, Tarlatzis BC: Among patients treated with FSH and $\mathrm{GnRH}$ analogues for in vitro fertilization, is the addition of recombinant LH associated with the probability of live birth? A systematic review and meta-analysis. Hum Reprod Update 2007, 13:445-452.

5. Hill MJ, Levy G, Levens ED: Does exogenous LH in ovarian stimulation improve assisted reproduction success? An appraisal of the literature. Reprod Biomed Online 2012, 24:261-271.

6. Musters AM, van Wely M, Mastenbroek S, Kaaijk EM, Repping S, van der Veen F, Mochtar MH: The effect of recombinant LH on embryo quality: a randomized controlled trial in women with poor ovarian reserve. Hum Reprod 2012, 27:244-250

7. Revelli A, Chiado A, Guidetti D, Bongioanni F, Rovei V, Gennarelli G: Outcome of in vitro fertilization in patients with proven poor ovarian responsiveness after early vs. mid-follicular LH exposure: a prospective, randomized, controlled study. J Assist Reprod Genet 2012, 29:869-875.

8. Sonmezer M, Iltemir Duvan C, Ozmen B, Tasci T, Ozkavukcu S, Atabekoglu CS: Outcomes after early or midfollicular phase LH supplementation in previous inadequate responders. Reprod Biomed Online 2010, 20:350-357.

9. Hill MJ, Levens ED, Levy G, Ryan ME, Csokmay JM, DeCherney AH, Whitcomb BW: The use of recombinant luteinizing hormone in patients undergoing assisted reproductive techniques with advanced reproductive age: a systematic review and meta-analysis. Fertil Steril 2012, 97:1108-1114. e1101.

10. Wong PC, Qiao J, Ho C, Ramaraju GA, Wiweko B, Takehara Y, Nadkarni PV, Cheng LC, Chen HF, Suwajanakorn S, Vuong TN: Current opinion on use of luteinizing hormone supplementation in assisted reproduction therapy: an Asian perspective. Reprod Biomed Online 2011, 23:81-90.

11. Konig TE, van der Houwen LE, Lambalk CB: Recombinant LH supplementation in women of 35 years and older undergoing IVF. Fertil Steril 2012, 98:e10-11. author reply e12.

12. Alviggi C, Clarizia R, Mollo A, Ranieri A, De Placido G: Who needs LH in ovarian stimulation? Reprod Biomed Online 2011, 22(Suppl 1):S33-41.

13. Venetis CA, Kolibianakis EM, Tarlatzi TB, Tarlatzis BC: Benefits of luteinizing hormone activity in ovarian stimulation for IVF. Reprod Biomed Online 2009, 18(Suppl 2):31-36.

14. Lisi F: To add or not to add LH: comments on recent commentaries. Reprod Biomed Online 2006, 12:415-417.

15. Franco JG Jr, Baruffi RL, Oliveira JB, Mauri AL, Petersen CG, Contart P, Felipe $\mathrm{V}$ : Effects of recombinant $\mathrm{LH}$ supplementation to recombinant FSH during induced ovarian stimulation in the GnRH-agonist protocol: a matched case-control study. Reprod Biol Endocrinol 2009, 7:58.

16. Kang HY, Tsai MY, Chang C, Huang KE: Mechanisms and clinical relevance of androgens and androgen receptor actions. Chang Gung Med J 2003, 26:388-402.

17. Chang SY, Kang HY, Lan KC, Chang CY, Huang FJ, Tsai MY, Huang KE: Expression of steroid receptors, their cofactors, and aromatase in human luteinized granulosa cells after controlled ovarian hyperstimulation. Fertil Steril 2005, 83(Suppl 1):1241-1247.

18. Rey R, Lukas-Croisier C, Lasala C, Bedecarras P: AMH/MIS: what we know already about the gene, the protein and its regulation. Mol Cell Endocrinol 2003, 211:21-31.

19. La Marca A, Sighinolfi G, Radi D, Argento C, Baraldi E, Artenisio AC, Stabile G, Volpe A: Anti-Mullerian hormone (AMH) as a predictive marker in assisted reproductive technology (ART). Hum Reprod Update 2010, 16:113-130.

20. Knight PG, Glister C: TGF-beta superfamily members and ovarian follicle development. Reproduction 2006, 132:191-206.

21. Erickson GF, Magoffin DA, Dyer CA, Hofeditz C: The ovarian androgen producing cells: a review of structure/function relationships. Endocr Rev 1985, 6:371-399.

22. Filicori M, Cognigni GE, Tabarelli C, Pocognoli P, Taraborrelli S, Spettoli D, Ciampaglia W: Stimulation and growth of antral ovarian follicles by selective LH activity administration in women. J Clin Endocrinol Metab 2002, 87:1156-1161.

23. Jeppesen JV, Nielsen ME, Kristensen SG, Yding Andersen C: Concentration of activin $\mathrm{A}$ and follistatin in follicular fluid from human small antral 
follicles associated to gene expression of the corresponding granulosa cells. Mol Cell Endocrinol 2012, 356:48-54.

24. Nielsen ME, Rasmussen IA, Kristensen SG, Christensen ST, Mollgard K, Wreford Andersen E, Byskov AG, Yding Andersen C: In human granulosa cells from small antral follicles, androgen receptor mRNA and androgen levels in follicular fluid correlate with FSH receptor mRNA. Mol Hum Reprod 2011, 17:63-70.

25. Eilso Nielsen M, Rasmussen IA, Fukuda M, Westergaard LG, Yding Andersen C Concentrations of anti-Mullerian hormone in fluid from small human antral follicles show a negative correlation with CYP19 mRNA expression in the corresponding granulosa cells. Mol Hum Reprod 2010, 16:637-643.

26. Sanchez F, Adriaenssens T, Romero S, Smitz J: Different follicle-stimulating hormone exposure regimens during antral follicle growth alter gene expression in the cumulus-oocyte complex in mice. Biol Reprod 2010, 83:514-524.

27. Pigny P, Merlen E, Robert Y, Cortet-Rudelli C, Decanter C, Jonard S, Dewailly $D$ : Elevated serum level of anti-mullerian hormone in patients with polycystic ovary syndrome: relationship to the ovarian follicle excess and to the follicular arrest. J Clin Endocrinol Metab 2003, 88:5957-5962.

28. Rose S, Laan MJ: Why match? Investigating matched case-control study designs with causal effect estimation. Int J Biostat 2009, 5:1

29. Lisi F, Rinaldi L, Fishel S, Lisi R, Pepe GP, Picconeri MG, Campbell A: Use of recombinant $\mathrm{LH}$ in a group of unselected IVF patients. Reprod Biomed Online 2002, 5:104-108.

30. Lan KC, Huang FJ, Lin YC, Kung FT, Lan TH, Chang SY: Significantly superior response in the right ovary compared with the left ovary after stimulation with follicle-stimulating hormone in a pituitary downregulation regimen. Fertil Steril 2010, 93:2269-2273.

31. Vanttinen T, Liu J, Hyden-Granskog C, Voutilainen R: Biphasic regulation of activin $A$ secretion by gonadotropins in cultured human ovarian granulosa-luteal cells leads to decreasing activin:inhibin ratios during continuing gonadotropin stimulation. J Endocrinol 2002, 172:557-563.

32. Hosokawa K, Dantes A, Schere-Levy C, Barash A, Yoshida Y, Kotsuji F, Vlodavsky I, Amsterdam A: Induction of Ad4BP/SF-1, steroidogenic acute regulatory protein, and cytochrome P450scc enzyme system expression in newly established human granulosa cell lines. Endocrinology 1998, 139:4679-4687.

33. Matzuk MM, Burns $\mathrm{KH}$, Viveiros MM, Eppig JJ: Intercellular communication in the mammalian ovary: oocytes carry the conversation. Science 2002, 296:2178-2180

34. McKenzie LJ, Pangas SA, Carson SA, Kovanci E, Cisneros P, Buster JE, Amato $P$, Matzuk MM: Human cumulus granulosa cell gene expression: a predictor of fertilization and embryo selection in women undergoing IVF. Hum Reprod 2004, 19:2869-2874.

35. Brannian J, Eyster K, Mueller BA, Bietz MG, Hansen K: Differential gene expression in human granulosa cells from recombinant FSH versus human menopausal gonadotropin ovarian stimulation protocols. Reprod Biol Endocrinol 2010, 8:25.

36. Macklon NS, Fauser BC: Follicle-stimulating hormone and advanced follicle development in the human. Arch Med Res 2001, 32:595-600.

37. Westergaard LG, Erb K, Laursen SB, Rasmussen PE, Rex S, Westergaard CG, Andersen CY: Concentrations of gonadotrophins and steroids in preovulatory follicular fluid and serum in relation to stimulation protocol and outcome of assisted reproduction treatment. Reprod Biomed Online 2004, 8:516-523.

38. Smitz J, Andersen AN, Devroey P, Arce JC: Endocrine profile in serum and follicular fluid differs after ovarian stimulation with HP-hMG or recombinant FSH in IVF patients. Hum Reprod 2007, 22:676-687.

39. Weenen C, Laven JS, Von Bergh AR, Cranfield M, Groome NP, Visser JA, Kramer P, Fauser BC, Themmen AP: Anti-Mullerian hormone expression pattern in the human ovary: potential implications for initial and cyclic follicle recruitment. Mol Hum Reprod 2004, 10:77-83.

40. Wunder DM, Guibourdenche J, Birkhauser MH, Bersinger NA: Anti-Mullerian hormone and inhibin $B$ as predictors of pregnancy after treatment by in vitro fertilization/intracytoplasmic sperm injection. Fertil Steril 2008, 90:2203-2210

41. Andersen CY, Lossl K: Increased intrafollicular androgen levels affect human granulosa cell secretion of anti-Mullerian hormone and inhibin-B. Fertil Steril 2008, 89:1760-1765.

42. Billig H, Furuta I, Hsueh AJ: Estrogens inhibit and androgens enhance ovarian granulosa cell apoptosis. Endocrinology 1993, 133:2204-2212.
43. Jonard S, Dewailly D: The follicular excess in polycystic ovaries, due to intra-ovarian hyperandrogenism, may be the main culprit for the follicular arrest. Hum Reprod Update 2004, 10:107-117.

44. de Santa BP, Moniot B, Poulat F, Berta P: Expression and subcellular localization of SF-1, SOX9, WT1, and AMH proteins during early human testicular development. Dev Dyn 2000, 217:293-298.

45. De Santa BP, Bonneaud N, Boizet B, Desclozeaux M, Moniot B, Sudbeck P, Scherer G, Poulat F, Berta P: Direct interaction of SRY-related protein SOX9 and steroidogenic factor 1 regulates transcription of the human anti-Mullerian hormone gene. Mol Cell Biol 1998, 18:6653-6665.

doi:10.1186/1477-7827-11-11

Cite this article as: Lan et al:: Analysis of androgen receptor and antiMüllerian hormone pathways in human granulosa cells under luteinizing hormone treatment. Reproductive Biology and Endocrinology 2013 11:11.

\section{Submit your next manuscript to BioMed Central and take full advantage of:}

- Convenient online submission

- Thorough peer review

- No space constraints or color figure charges

- Immediate publication on acceptance

- Inclusion in PubMed, CAS, Scopus and Google Scholar

- Research which is freely available for redistribution 